\title{
Effective Elastic Properties of Honeycomb Core with Fiber-Reinforced Composite Cells
}

\section{F. Ernesto Penado}

Department of Mechanical Engineering, Northern Arizona University, Flagstaff, USA.

Email: Ernesto.Penado@nau.edu

Received August $18^{\text {th }}, 2013$; revised September 10 $0^{\text {th }}, 2013$; accepted September $18^{\text {th }}, 2013$

Copyright (C) 2013 F. Ernesto Penado. This is an open access article distributed under the Creative Commons Attribution License, which permits unrestricted use, distribution, and reproduction in any medium, provided the original work is properly cited.

\begin{abstract}
Sandwich construction incorporating a honeycomb cellular core offers the attainment of structures that are very stiff and strong in bending while the weight is kept at a minimum. Generally, an aluminum or Nomex honeycomb core is used in applications requiring sandwich construction with fiber-reinforced composite facesheets. However, the use of a fiberreinforced composite core offers the potential for even lower weight, increased stiffness and strength, low thermal distortion compatible with that of the facesheets, the absence of galvanic corrosion and the ability to readily modify the core properties to suit specialized needs. Furthermore, the material of the core itself will exhibit anisotropic material properties in this case. In order to design, analyze and optimize these structures, knowledge of the effective mechanical properties of the core is essential. In this paper, the effective three-dimensional mechanical properties of a composite hexagonal cell core are determined using a numerical method based on a finite element analysis of a representative unit cell. In particular, the geometry of the simplest repeating unit of the core as well as the appropriate loading and boundary conditions that must be applied is presented.
\end{abstract}

Keywords: Lightweight Structures; Composite Mirrors; Sandwich Construction; Hexagonal Cell Core; Effective Core Properties

\section{Introduction}

Sandwich structures can be used advantageously where low weight and high stiffness and strength are required, such as the traditional case in aerospace applications. Composite materials, such as carbon fiber reinforced plastics (CFRP), are well suited for sandwich construction methods due to their low weight, high stiffness, high strength, dimensional stability, and ease of manufacture. For example, complex structural designs can be fabricated in CFRP directly and do not need massive material removal to achieve the desired shape, which would be the case with traditional materials such as aluminum. A sandwich structure consisting of two face-sheets (skins) bonded to a framework of ribs between them is much lighter than a solid sheet of the same material but retains most of the stiffness in bending. The stiffness against bending out of plane is a strong function of the facesheet planar stiffness and the distance between the two facesheets (e.g., the moment of inertia), providing the core carries the entire shear load. Sandwich construction is very common in a wide variety of applications, including aircraft components, space structures, and other weight sensitive applications. More recently, other non-traditional applications have emerged, such as in land and sea transportation [1] and in the construction of optical telescope composite mirrors $[2,3]$. The latter requires very tight tolerances of dimensional stability and low weight, so a core made of CFRP material that is very stiff and at the same time has thermal expansion compatible with that of the facesheets can be used advantageously. In order to facilitate the analysis and design of these structures, the core can be represented as a homogeneous layer with equivalent mechanical properties.

The effective properties of the core can be found analytically, numerically or experimentally [4]. Existing analytical methods to find the equivalent homogeneous properties of the core are based on isotropic material properties (e.g. aluminum) and use a variety of simplifying assumptions. Notably, Kelsey et al. [5] used the unit displacement and unit load methods in conjunction with simplifying assumptions to derive simple expressions for the upper and lower limits of the shear moduli of honeycomb sandwich cores. Hoffman [6] used an en- 
ergy method to derive an expression for the in-plane Poisson ratio. Zhang and Ashby [7] adapted the analysis of Gibson and Ashby [8] for honeycombs with a pair of doubled walls in each hexagonal cell to derive effective out-of-plane properties. Later, Masters and Evans [9] combined the three mechanisms of flexing, hinging and stretching to derive in-plane effective properties of the core for the tensile and shear moduli, and Poisson's ratio. Grediac [10] used finite element analyses and the upper and lower bounds to determine a least squares approximation for the transverse shear moduli. However, due to the complexities involved, analytical solutions for a core with walls made of CFRP materials, which are anisotropic in nature, are not currently available.

In a previous paper, Penado et al. [2] presented a numerical method to find the mechanical properties of a triangular isogrid core with composite (anisotropic) walls. In the present paper, a practical method is presented to determine the effective elastic properties of a hexagonal cell core from a finite element analysis of the simplest repeating unit of the core, including the proper boundary conditions that must be used in the model. In applications that require structural stability, such as composite mirrors, hexagonal cells offer the advantage of higher out-ofplane shear stiffness over triangular cells of the same density.

\section{Unit Cell Method}

A hexagonal cell core exhibits a regular, periodic pattern. Although a full core can be difficult or impractical to model due to its complexity, a significant amount of simplification can be achieved by considering only the representative structural unit, or unit cell, as shown in Figure 1. However, this unit cell is not the simplest repeating unit that must be used in the finite element model, as shown later. By proper selection of boundary conditions and loading, the properties obtained by using the unit cell equal those of the full core. It should be noted that, due to the expansion process used in the manufacture of hexagonal-cell cores, the thickness of the hori-

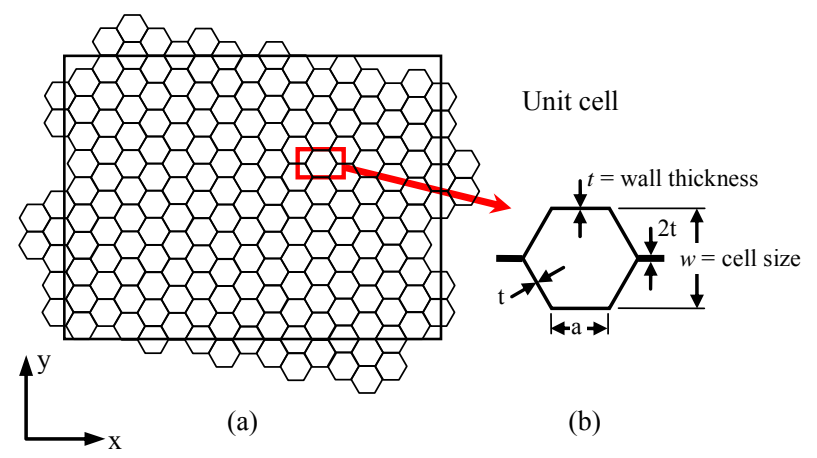

Figure 1. (a) Plan view of full hexagonal cell core; (b) Unit cell. zontal cell wall is usually twice the thickness of the inclined cell walls, and this is the case considered herein (see Figure 1).

The effective stiffnesses of the core are determined by finding the force necessary to produce an unit displacement in a given direction, determining the resulting stress and strain, and then calculating the corresponding engineering constants. This process can be used to find the nine effective engineering constants, $E_{x}, E_{y}, E_{z}, G_{x y}, G_{x z}$, $G_{y z}, v_{x y}, v_{x z}$, and $v_{y z}$. In equation form,

$$
\begin{gathered}
E_{i}=\frac{\sigma_{i}}{\varepsilon_{i}}=\frac{F_{i} / A_{i}}{u_{i} / L_{i}} \\
v_{i j}=-\frac{\varepsilon_{j}}{\varepsilon_{i}}=-\frac{u_{i j} / L_{j}}{u_{i} / L_{i}} \\
G_{i j}=\frac{\tau_{i j}}{\gamma_{i j}}=\frac{F_{j} / A_{i}}{u_{j} / L_{i}}
\end{gathered}
$$

where $i, j=x, y$ or $z$ directions; $E_{i}=$ extension modulus in $i$-direction; $v_{i j}=$ Poisson's ratio; $G_{i j}=$ shear modulus in $i-j$ plane; $\sigma_{i}=$ normal stress in $i$-direction; $\varepsilon_{i}=$ normal strain in $i$-direction; $\tau_{i j}=$ shear stress in $i-j$ plane; $\gamma_{i j}=$ shear strain in $i-j$ plane; $A_{i}, A_{j}=$ projected area of core on a plane perpendicular to $i-, j$-direction; $L_{i}, L_{j}=$ length of core in $i-, j$-direction; $F_{i}, F_{j}=$ force needed to produce a unit displacement $u_{i}, u_{j} ; u_{i}, u_{j}=$ unit displacement in $i-$, $j$-direction $=1$; and $u_{i j}=$ resulting displacement in $j$-direction when a unit displacement is applied in $i$-direction. For example,

$$
\begin{gathered}
E_{x}=\frac{\sigma_{x}}{\varepsilon_{x}}=\frac{F_{x} / A_{x}}{u_{x} / L_{x}}=\frac{F_{x} L_{x}}{(1) A_{x}} \\
v_{x y}=-\frac{\varepsilon_{y}}{\varepsilon_{x}}=-\frac{u_{x y} / L_{y}}{u_{x} / L_{x}}=-\frac{u_{x y} L_{x}}{(1) L_{y}} \\
G_{x y}=\frac{\tau_{x y}}{\gamma_{x y}}=\frac{F_{y} / A_{x}}{u_{y} / L_{x}}=\frac{F_{y} L_{x}}{(1) A_{x}}
\end{gathered}
$$

The application of the appropriate boundary conditions and unit displacements to the unit cell is discussed in the next section. It should be noted that, as part of the verification process involving symmetry conditions, the following six additional effective engineering constants were also calculated: $G_{y x}, G_{z x}, G_{z y}, v_{y x}, v_{z x}$, and $v_{z y}$.

\section{Finite Element Model and Boundary Conditions}

\subsection{Finite Element Model of Unit Cell}

Closed form solutions for the effective properties of a core with hexagonal cells can be found in the literature only for the special case of isotropic walls, such as those made of aluminum $[7,9,11]$. Cell walls made of compos- 
ite materials, such as carbon fiber reinforced plastics, present additional complications due to the inherent heterogeneous and anisotropic nature of these materials. In fact, even if the material is layed-up in a quasi-isotropic configuration (that is, exhibiting isotropic behavior in the plane of the material), the in-plane and flexural stiffnesses will have different values due to the layered nature of the composite laminate [12]. Thus, the flexural stiffnesses will depend on the lay-up sequence, while the in-plane stiffnesses will not. Furthermore, since the deformation mechanisms in honeycomb cells can include flexure, stretching and hinging [9], the results for isotropic core materials may not apply when composite materials are used.

The finite element method provides an effective way to deal with the anisotropic and heterogeneous behavior of composite cell walls. However, and although the finite element model of the unit cell is simple, a difficulty normally found in this process is the determination of the appropriate boundary conditions that must be applied to the model in order to replicate the behavior of the overall core. The determination of these boundary conditions is dependent upon the overall behavior expected. For the present case of hexagonal cells, these boundary conditions were determined by careful study and evaluation of the expected loading, deformation and symmetry conditions of the 1/8 segment of the unit cell shown in Figure 2(b), and are summarized in Table 1. Note that, as shown in Figures 2(a) and (b), only 1/8 of a unit cell is needed in the finite element model due to the symmetry of the unit cell in the $x, y$ and $z$ directions. Therefore, a simple finite element mesh consisting of laminated composite shell elements, as shown in Figure 3(b), is all that is needed to obtain the same results as if the full core (containing a repeating pattern of unit cells) were modeled. Figure 3(b) also shows the labeling of the edges and surfaces used in the definition of the boundary conditions in Table 1. The boundary conditions presented in Table 1 were verified as discussed next.

\subsection{Verification of the Boundary Conditions of the Model}

In order to verify the finite element model and, in particular, the validity of the boundary conditions used, results for an aluminum core obtained by the present method were compared with theoretical and experimental results from the literature for the special case of isotropic cell walls (aluminum). The comparison of results is given in Table 2. The core properties used were $w=6.35 \mathrm{~mm}$, $h=20 \mathrm{~mm}, t=0.0635 \mathrm{~mm}, E=68.9 \mathrm{GPa}, v=0.33$ and $\rho_{m}=$ density of the raw material $=2704 \mathrm{~kg} / \mathrm{m}^{3}$. For the finite element results, two conditions are possible at the interface between the core and the facesheet: wall free and wall fixed. The wall free condition corresponds to the case where the facesheet has no restraining effect on the core and is the case shown in Table 1. On the other hand, for the wall fixed condition, the facesheet completely prevents the core from rotation at the interface.

Table 1. Boundary conditions needed for the proper modeling a 1/8 segment of a unit cell. Edges and surfaces are defined in Figure 3b.

\begin{tabular}{|c|c|c|c|c|c|c|c|c|c|}
\hline \multirow{2}{*}{$\begin{array}{l}\text { Location } \\
\text { (see Figure } \\
\text { 3(b)) }\end{array}$} & \multicolumn{9}{|c|}{ Boundary conditions $^{\dagger}$} \\
\hline & $E_{x}, v_{x y}$ and $v_{x z}$ & $E_{y}, v_{y x}$ and $v_{y z}$ & $E_{z}, v_{z x}$ and $v_{z y}$ & $G_{x y}$ & $G_{y x}$ & $G_{x z}$ & $G_{z x}$ & $G_{y z}$ & $G_{z y}$ \\
\hline E1 & $\mathrm{SZ}$ & $\mathrm{SZ}$ & SZ & $\mathrm{SZ}$ & $\mathrm{SZ}$ & $\mathrm{AZ}$ & $\mathrm{AZ}$ & $\mathrm{AZ}$ & $\mathrm{AZ}$ \\
\hline E2 & $\mathrm{SZ}$ & $\mathrm{SZ}$ & $\mathrm{SZ}$ & $\mathrm{SZ}$ & $\mathrm{SZ}$ & $\mathrm{AZ}$ & $\mathrm{AZ}$ & $\mathrm{AZ}$ & $\mathrm{AZ}$ \\
\hline E3 & SZ & SZ & SZ & $\mathrm{SZ}$ & $\mathrm{SZ}$ & $\mathrm{AZ}$ & $\mathrm{AZ}$ & $\mathrm{AZ}$ & $\mathrm{AZ}$ \\
\hline E4 & $\begin{array}{l}u_{z} \text { uniform } \\
\text { (CPDOF) }\end{array}$ & $\begin{array}{l}u_{z} \text { uniform } \\
\text { (CPDOF) }\end{array}$ & $u_{z}=1$ & free & free & $u_{x}=u_{y}=0$ & $\begin{array}{c}u_{x}=1 \\
u_{y}=u_{z}=0\end{array}$ & $u_{x}=u_{y}=0$ & $\begin{array}{c}u_{y}=1 \\
u_{x}=u_{z}=0\end{array}$ \\
\hline E5 & $\begin{array}{l}u_{z} \text { uniform } \\
\text { (CPDOF) }\end{array}$ & $\begin{array}{l}u_{z} \text { uniform } \\
\text { (CPDOF) }\end{array}$ & $u_{z}=1$ & free & free & $u_{x}=u_{y}=0$ & $\begin{array}{c}u_{x}=1 \\
u_{y}=u_{z}=0\end{array}$ & $u_{x}=u_{y}=0$ & $\begin{array}{c}u_{y}=1 \\
u_{x}=u_{z}=0\end{array}$ \\
\hline E6 & $\begin{array}{l}u_{z} \text { uniform } \\
\text { (CPDOF) }\end{array}$ & $\begin{array}{l}u_{z} \text { uniform } \\
\text { (CPDOF) }\end{array}$ & $u_{z}=1$ & free & free & $u_{x}=u_{y}=0$ & $\begin{array}{c}u_{x}=1 \\
u_{y}=u_{z}=0\end{array}$ & $u_{x}=u_{y}=0$ & $\begin{array}{c}u_{y}=1 \\
u_{x}=u_{z}=0\end{array}$ \\
\hline E7 & $u_{x}=1$ & $\begin{array}{l}u_{x} \text { uniform } \\
\text { (CPDOF) }\end{array}$ & $u_{x}$ uniform $(\mathrm{CPDOF})$ & $u_{y}=1$ & $\mathrm{AX}$ & $\begin{array}{c}u_{z}=1 \\
u_{x}=u_{y}=0\end{array}$ & $\mathrm{AX}$ & SX & SX \\
\hline E8 & SX & SX & SX & $\mathrm{AX}$ & $\mathrm{AX}$ & $\mathrm{AX}$ & $\mathrm{AX}$ & SX & SX \\
\hline S1 & SY & SY & SY & AY & AY & SY & SY & AY & AY \\
\hline S2 & $\begin{array}{c}u_{y} \text { uniform }(\mathrm{CPDOF}) \\
\mathrm{AR}=0\end{array}$ & $\begin{array}{l}u_{y}=-1 \\
\mathrm{AR}=0\end{array}$ & $\begin{array}{c}u_{y} \text { uniform }(\mathrm{CPDOF}) \\
\mathrm{AR}=0\end{array}$ & AY & $\begin{array}{c}u_{x}=-1 \\
u_{y}=u_{z}=0\end{array}$ & SY & SY & $\begin{array}{c}u_{z}=-1 \\
u_{x}=u_{y}=0\end{array}$ & AY \\
\hline
\end{tabular}

${ }^{\dagger} \mathrm{SX}, \mathrm{SY}, \mathrm{SZ}=$ symmetry conditions with respect to a plane perpendicular to the $\mathrm{X}, \mathrm{Y}, \mathrm{Z}$ axis; AX, AY, AZ = anti-symmetry conditions with respect to a plane perpendicular to the $\mathrm{X}, \mathrm{Y}, \mathrm{Z}$ axis; $u_{x}, u_{y}, u_{z}=$ displacement in the $x, y, z$ direction; $\mathrm{CPDOF}=$ coupled degrees of freedom; $\mathrm{AR}=$ all rotations. 
Table 2. Comparison of results for aluminum core for verification of the boundary conditions in the finite element model.

\begin{tabular}{|c|c|c|c|c|c|c|}
\hline \multirow{3}{*}{ Property } & \multicolumn{4}{|c|}{ Present results } & \multicolumn{2}{|c|}{ Literature } \\
\hline & \multicolumn{2}{|c|}{ 4-noded elements } & \multicolumn{2}{|c|}{ 8-noded elements } & \multirow{2}{*}{$\begin{array}{l}\text { Theoretical } \\
\text { (wall free) }\end{array}$} & \multirow{2}{*}{ Experimental } \\
\hline & Wall free & Wall fixed & Wall free & Wall fixed & & \\
\hline$E_{x}(\mathrm{GPa})$ & 0.000924 & 0.00399 & 0.000924 & 0.00279 & 0.000827 [9] & - \\
\hline$E_{y}(\mathrm{GPa})$ & 0.000924 & 0.00399 & 0.000924 & 0.00279 & 0.000827 [9] & - \\
\hline$E_{z}(\mathrm{GPa})$ & 1.84 & 1.84 & 1.84 & 1.84 & $1.84[7]$ & $\begin{array}{c}1.0(\text { Hexcel })[13] \\
1.03(\text { ASTM })[13] \\
1.89 \text { (Dynamic method) }[13]\end{array}$ \\
\hline$v_{x y}$ & 0.999 & 0.996 & 0.999 & 0.997 & 0.999 [9] & - \\
\hline$v_{y x}$ & 0.999 & 0.994 & 0.999 & 0.996 & 0.999 [9] & - \\
\hline$v_{x z}$ & 0.000165 & 0.000716 & 0.000166 & 0.000500 & $\approx 0[7]$ & - \\
\hline$v_{z x}$ & 0.329 & 0.330 & 0.330 & 0.330 & $0.33[7]$ & - \\
\hline$v_{y z}$ & 0.000166 & 0.000715 & 0.000166 & 0.000499 & $\approx 0[7]$ & - \\
\hline$v_{z y}$ & 0.331 & 0.330 & 0.330 & 0.330 & $0.33[7]$ & - \\
\hline$G_{x y}(\mathrm{GPa})$ & 0.000347 & 0.00256 & 0.000346 & 0.00168 & $0.000207[9]$ & - \\
\hline$G_{y x}(\mathrm{GPa})$ & 0.000448 & 0.00196 & 0.000454 & 0.00137 & - & - \\
\hline$G_{x Z}(\mathrm{GPa})$ & 0.389 & 0.389 & 0.389 & 0.389 & $0.395[10]$ & $\begin{array}{c}0.44 \text { (Hexcel) [13] } \\
0.465 \text { (ASTM) [13] } \\
0.369 \text { (Dynamic method) [13] }\end{array}$ \\
\hline$G_{z x}(\mathrm{GPa})$ & 0.395 & 0.395 & 0.395 & 0.395 & - & - \\
\hline$G_{y z}(\mathrm{GPa})$ & 0.259 & 0.259 & 0.259 & 0.259 & $0.259[10]$ & $\begin{array}{c}0.22(\text { Hexcel })[13] \\
0.251 \text { (ASTM) [13] } \\
0.217 \text { (Dynamic method) [13] }\end{array}$ \\
\hline$G_{z y}(\mathrm{GPa})$ & 0.259 & 0.259 & 0.259 & 0.259 & - & - \\
\hline
\end{tabular}

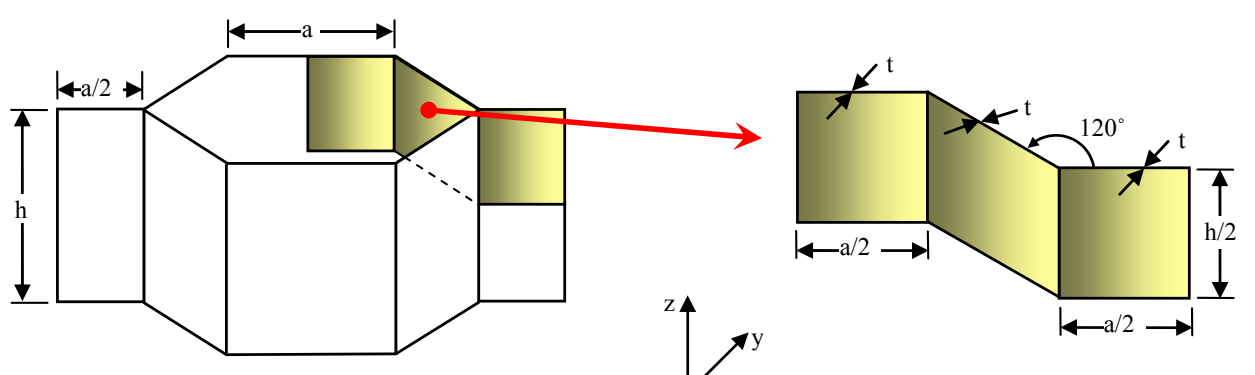

(a)

(b)

Figure 2. (a) 3D view of unit cell; (b) 1/8 segment used in finite element analysis due to symmetry conditions of the unit cell.

The actual interface conditions are in between these two extreme cases due to the elasticity of the bonded interface between the facesheet and core. Note that the boundary conditions for the wall fixed case can be obtained from those given in Table 1 by imposing the additional constraint that $\mathrm{AR}=$ all rotations $=0$ at edges $\mathrm{E} 4$, E5 and E6. In addition, the effect of the order of the elements was investigated by considering 4-noded and 8noded shell elements. The results were virtually identical for 4- and 8-noded elements for wall free conditions and a small difference in the wall fixed case for the relatively small in-plane properties $\left(E_{x}, E_{y}, G_{x y}\right.$ and $\left.G_{y x}\right)$ and the near zero Poisson's ratios $\left(v_{x z}\right.$ and $\left.v_{y z}\right)$. Hence, only 4noded elements are used hereafter. It can be seen in Table 2 that there is good agreement between the literature results and the present finite element solution. The difference is most likely due to the approximate nature of the theoretical results, which are based on mechanics of materials approximations. The few experimental results available are reasonably close to the present results, especially when one considers the difficulties inherent in measuring the elastic properties of the core [13]. It is interesting to note that virtually no difference in values is observed between the wall free and wall fixed conditions 


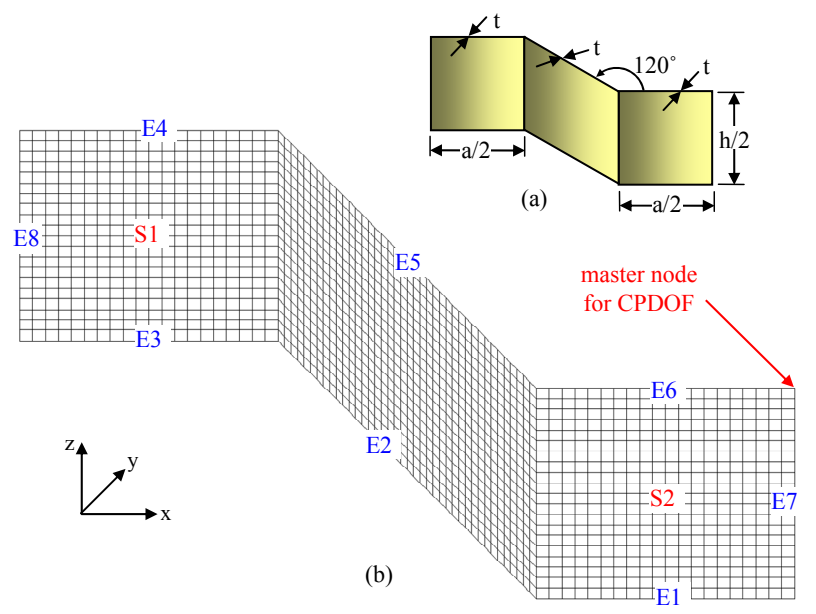

Figure 3. (a) 1/8 segment used in finite element analysis; (b) Typical finite element mesh used showing the labeling of edges (E) and surfaces (S).

for the properties not small or near zero $\left(E_{z}, v_{x y}, v_{y x}, v_{z x}\right.$, $v_{z y}, G_{x z}, G_{z x}, G_{y z}$ and $\left.G_{z y}\right)$. However, this is not necessarily the case with other cell dimensions, wall thicknesses, and when composite cells are considered, as seen in Tables 4 and 6, especially for the Poisson's ratios. However, the difference is small and either the wall free or wall fixed boundary conditions can be used to approximate the effective elastic properties of the core.

An additional check is provided by noting that the symmetry of the stiffness constants requires that the following relations be satisfied [12]:

$$
\begin{gathered}
G_{x y}=G_{x y}, G_{x z}=G_{z x}, G_{y z}=G_{z y} \\
v_{y x}=\frac{E_{y}}{E_{x}} v_{x y}, v_{z x}=\frac{E_{z}}{E_{x}} v_{x z}, v_{z y}=\frac{E_{z}}{E_{y}} v_{y z}
\end{gathered}
$$

In order to perform this check, the properties $G_{y z}, G_{z x}$, $G_{z y}, v_{y x}, v_{z x}$ and $v_{z y}$ were additionally calculated. The appropriate boundary conditions for these cases are also given in Table 1. It can be seen that the results in Table 2 either equally or very nearly satisfy Equations (7), (8), providing an additional check on the results. The only case where there is a small discrepancy is in the in-plane shear modulus, $G_{x y}$. This discrepancy may be explained by the relatively small value of $G_{x y}$ with respect to the out-of-plane shear moduli, $G_{x z}$ and $G_{y z}$, which are roughly 2 - 3 orders of magnitude smaller. It should be noted that Chamis [14] noticed a similar small discrepancy between $G_{x y}$ and $G_{y x}$ using a completely different approach based on a three dimensional detailed finite element model of the honeycomb that included multiple cells. His results were based on "wall free" conditions for the cells. Chamis also observed a much smaller discrepancy between $G_{x z}$ and $G_{z x}$ and exact equality between $G_{y z}$ and $G_{z y}$, all consistent with the present results.

\section{Results for Anisotropic Cells and Discussion}

The 1/8 segment of a unit cell shown in Figure 3(a) was modeled using version 2.95 of the finite element code COSMOS/M [15]. This finite element code includes, in its library, a layered composite element with a capacity of up to fifty layers, and is suitable for the analysis of structures made of composite materials. The finite element mesh used herein is shown in Figure 3(b) and consisted of 1,701 nodes and 1,600 four-noded composite shell elements. The boundary conditions used are those shown in Table 1. A cell size of $25.4 \mathrm{~mm}$ and three layups $\left([45 /-45]_{s},[0 / \pm 60]_{s}\right.$, and $\left.[0 \pm 53.5 / 90]_{s}\right)$ were considered. All of the layups used result in a relatively low coefficient of thermal expansion in the walls of the core and were chosen because they provide different conditions of practical importance. The $[45 /-45]_{\mathrm{s}}$ laminate has the smallest thickness and highest in-plane shear, but its other elastic properties are relatively low. The $[0 / \pm 60]_{s}$ laminate is a quasi-isotropic laminate with intermediate thickness. The $[0 / \pm 53.5 / 90]_{\mathrm{s}}$ laminate has near zero coefficient of thermal expansion in the x-direction (see footnote under Table 3), but has the highest thickness. In each case, a larger thickness means higher density. For the various cell sizes, the cell height used was the same as the cell size, $h=a$. The same number of elements and nodes were used in each case, although the element size was scaled up or down depending on the cell size. The ply (lamina) material used consisted of a high modulus pitch fiber with a cyanate ester matrix, and has the properties given in Table 5 [16]. As a result of its high stiffness and dimensional stability due to its hygrophobic nature, this material system is well suited for use in composite mirror applications. Furthermore, the thermoelastic laminate properties for each laminate, calculated from laminated plate theory [12], are given in Table 3 along with the corresponding properties of aluminum for comparison. The equivalent stiffnesses for the core resulting from the analysis are given in Tables $\mathbf{4}$ and $\mathbf{6}$, respectively, for the cases of free and fixed boundary conditions at edges E4, E5 and E6 (Figure 3b). The results for the composite (anisotropic) core are compared with those of aluminum core of the same density. For a hexagonal core, the dimensionless relative density, defined as the ratio of the core density $\rho$ to the density of the raw material $\rho_{m}$, can be expressed in terms of the wall thickness and cell size as:

$$
\begin{aligned}
C & \equiv \frac{\rho}{\rho_{m}}=\frac{m_{\text {wall }}}{m_{\text {cell }}}=\frac{\rho_{m} V_{\text {wall }}}{\rho_{m} V_{\text {cell }}}=\frac{A_{\text {wall }}}{A_{\text {cell }}} \\
& =\frac{(a / 2+a+a / 2) t}{(\sqrt{3} / 2) a(a / 2+a / 2+a / 2)}=\frac{8}{3 \sqrt{3}} \times \frac{t}{a}
\end{aligned}
$$

where the cell used corresponds to the $1 / 8$ segment in 
Table 3. In-plane thermoelastic properties for the various laminate configurations used in the cell wall.

\begin{tabular}{|c|c|c|c|c|}
\hline \multirow{2}{*}{ Property ${ }^{*}$} & \multirow{2}{*}{$\begin{array}{l}\text { Aluminum } \\
\text { (Isotropic) }\end{array}$} & \multicolumn{3}{|c|}{ Composite layup } \\
\hline & & {$[45 /-45]_{\mathrm{s}}$ (Angle-ply) } & {$[0 / \pm 60]_{\mathrm{s}}$ (Quasi-isotropic) } & {$[0 / \pm 53.5 / 90]_{\mathrm{s}}(0-\mathrm{CTE})$} \\
\hline Material density, $\rho_{m}\left(\mathrm{~kg} / \mathrm{m}^{3}\right)$ & 2704 & 1710 & 1710 & 1710 \\
\hline$E_{x}$, in-plane $(\mathrm{GPa})$ & 68.9 & 20.7 & 99.3 & 84.8 \\
\hline$E_{x}$, flexural $(\mathrm{GPa})$ & 68.9 & 19.1 & 199.3 & 167.5 \\
\hline$E_{y}$, in-plane $(\mathrm{GPa})$ & 68.9 & 20.7 & 99.3 & 122.0 \\
\hline$E_{y}$, flexural $(\mathrm{GPa})$ & 68.9 & 19.1 & 31.4 & 45.8 \\
\hline$v_{x y}$ & 0.33 & 0.856 & 0.307 & 0.233 \\
\hline$G_{x y}(\mathrm{GPa})$ & 25.9 & 70.3 & 37.9 & 35.2 \\
\hline$\alpha_{x}\left(\left.\mu \varepsilon\right|^{\circ} \mathrm{C}\right)$ & 23.0 & -0.409 & -0.409 & -0.00374 \\
\hline$\alpha_{y}\left(\mu \varepsilon /^{\circ} \mathrm{C}\right)$ & 23.0 & -0.409 & -0.409 & -0.713 \\
\hline
\end{tabular}

*The $x$-direction corresponds to the direction perpendicular to the $z$-axis in the plane of the cell wall.

Table 4. Equivalent stiffnesses of aluminum and composite cores of equal densities with free cell wall conditions.

\begin{tabular}{|c|c|c|c|c|c|c|c|c|c|}
\hline \multirow{3}{*}{$\begin{array}{l}\text { Property } \\
\text { Layup }\end{array}$} & \multicolumn{9}{|c|}{ Equivalent stiffness from finite element model, free wall, 4-noded elements } \\
\hline & \multicolumn{3}{|c|}{ Aluminum cell, $w=25.4 \mathrm{~mm}$} & \multicolumn{3}{|c|}{ Composite cell, $w=25.4 \mathrm{~mm}$} & \multicolumn{3}{|c|}{ Ratio Composite/Aluminum } \\
\hline & - & - & - & {$[45 /-45]_{\mathrm{s}}$} & {$[0 / \pm 60]_{\mathrm{s}}$} & {$[0 / \pm 53.5 / 90]_{\mathrm{s}}$} & {$[45 /-45]_{\mathrm{s}}$} & {$[0 / \pm 60]_{\mathrm{s}}$} & {$[0 / \pm 53.5 / 90]_{\mathrm{s}}$} \\
\hline Wall thickness, $t(\mathrm{~mm})$ & 0.353 & 0.531 & 0.709 & 0.559 & 0.838 & 1.12 & - & - & - \\
\hline Core density, $\rho\left(\mathrm{kg} / \mathrm{m}^{3}\right)$ & 100.3 & 150.7 & 200.9 & 100.3 & 150.7 & 200.9 & 1 & 1 & 1 \\
\hline$E_{x}(\mathrm{GPa})$ & 0.00248 & 0.00834 & 0.0198 & 0.00685 & 0.0772 & 0.150 & 2.76 & 9.26 & 7.56 \\
\hline$E_{y}(\mathrm{GPa})$ & 0.00248 & 0.00834 & 0.0197 & 0.00684 & 0.0772 & 0.148 & 2.76 & 9.26 & 7.52 \\
\hline$E_{\mathrm{z}}(\mathrm{GPa})$ & 2.56 & 3.84 & 5.12 & 1.21 & 8.76 & 14.3 & 0.473 & 2.28 & 2.80 \\
\hline$G_{x y}(\mathrm{GPa})$ & 0.000931 & 0.00313 & 0.00738 & 0.00243 & 0.0235 & 0.0447 & 2.61 & 7.51 & 6.07 \\
\hline$G_{y x}(\mathrm{GPa})$ & 0.00122 & 0.00411 & 0.00972 & 0.00459 & 0.0431 & 0.0807 & 3.76 & 10.5 & 8.30 \\
\hline$G_{x z}(\mathrm{GPa})$ & 0.542 & 0.814 & 1.08 & 2.32 & 1.88 & 2.32 & 4.27 & 2.31 & 2.14 \\
\hline$G_{z x}(\mathrm{GPa})$ & 0.569 & 0.855 & 1.14 & 2.35 & 1.97 & 2.45 & 4.13 & 2.31 & 2.15 \\
\hline$G_{y z}(\mathrm{GPa})$ & 0.361 & 0.542 & 0.724 & 1.54 & 1.25 & 1.54 & 4.27 & 2.30 & 2.13 \\
\hline$G_{z y}(\mathrm{GPa})$ & 0.361 & 0.542 & 0.724 & 1.54 & 1.25 & 1.54 & 4.27 & 2.30 & 2.13 \\
\hline$v_{x y}$ & 0.998 & 0.996 & 0.993 & 0.989 & 0.984 & 0.973 & 0.991 & 0.988 & 0.980 \\
\hline$v_{y x}$ & 0.998 & 0.994 & 0.990 & 0.988 & 0.977 & 0.961 & 0.990 & 0.983 & 0.971 \\
\hline$v_{x z}$ & 0.000319 & 0.000717 & 0.00127 & 0.00483 & 0.00273 & 0.00350 & 15.1 & 3.81 & 2.76 \\
\hline$v_{z x}$ & 0.329 & 0.329 & 0.330 & 0.854 & 0.307 & 0.335 & 2.60 & 0.933 & 1.02 \\
\hline$v_{y z}$ & 0.000320 & 0.000719 & 0.00127 & 0.00484 & 0.00271 & 0.00347 & 15.1 & 3.77 & 2.73 \\
\hline$v_{z y}$ & 0.331 & 0.331 & 0.330 & 0.858 & 0.308 & 0.336 & 2.59 & 0.931 & 1.02 \\
\hline
\end{tabular}

Table 5. Fiber-reinforced composite lamina material properties used in the analysis.

\begin{tabular}{cccccccc}
\hline$E_{1}(\mathrm{GPa})$ & $E_{2}(\mathrm{GPa})$ & $v_{12}$ & $G_{12}(\mathrm{GPa})$ & $\alpha_{1}\left(\mu \varepsilon /^{\circ} \mathrm{C}\right)$ & $\alpha_{2}\left(\mu \varepsilon /{ }^{\circ} \mathrm{C}\right)$ & Density, $\rho_{m}\left(\mathrm{~kg} / \mathrm{m}^{3}\right)$ & Ply thickness $(\mathrm{mm})$ \\
\hline 279 & 3.93 & 0.324 & 5.56 & -1.31 & 48.2 & 1710 & 0.140 \\
\hline
\end{tabular}


Table 6. Equivalent stiffnesses of aluminum and composite cores of equal densities with fixed cell wall conditions.

\begin{tabular}{|c|c|c|c|c|c|c|c|c|c|}
\hline \multirow{3}{*}{$\begin{array}{l}\text { Property } \\
\text { Layup }\end{array}$} & \multicolumn{9}{|c|}{ Equivalent stiffness from finite element model, fixed wall, 4-noded elements } \\
\hline & \multicolumn{3}{|c|}{ Aluminum cell, $w=25.4 \mathrm{~mm}$} & \multicolumn{3}{|c|}{ Composite cell, $w=25.4 \mathrm{~mm}$} & \multicolumn{3}{|c|}{ Ratio Composite/Aluminum } \\
\hline & - & - & - & {$[45 /-45]_{\mathrm{s}}$} & {$[0 / \pm 60]_{\mathrm{s}}$} & {$[0 / \pm 53.5 / 90]_{\mathrm{s}}$} & {$[45 /-45]_{\mathrm{s}}$} & {$[0 / \pm 60]_{\mathrm{s}}$} & {$[0 / \pm 53.5 / 90]_{\mathrm{s}}$} \\
\hline Wall thickness, $t(\mathrm{~mm})$ & 0.353 & 0.531 & 0.709 & 0.559 & 0.838 & 1.12 & - & - & - \\
\hline Core density, $\rho\left(\mathrm{kg} / \mathrm{m}^{3}\right)$ & 100.3 & 150.7 & 200.9 & 100.3 & 150.7 & 200.9 & 1 & 1 & 1 \\
\hline$E_{x}(\mathrm{GPa})$ & 0.0596 & 0.186 & 0.403 & 0.0275 & 0.101 & 0.199 & 0.462 & 0.544 & 0.493 \\
\hline$E_{y}(\mathrm{GPa})$ & 0.0585 & 0.179 & 0.379 & 0.0274 & 0.100 & 0.195 & 0.468 & 0.558 & 0.515 \\
\hline$E_{z}(\mathrm{GPa})$ & 2.56 & 3.84 & 5.12 & 1.21 & 8.76 & 14.3 & 0.473 & 2.28 & 2.80 \\
\hline$G_{x y}(\mathrm{GPa})$ & 0.0412 & 0.125 & 0.265 & 0.0137 & 0.0389 & 0.0724 & 0.333 & 0.312 & 0.273 \\
\hline$G_{y x}(\mathrm{GPa})$ & 0.0290 & 0.0896 & 0.194 & 0.0182 & 0.0599 & 0.111 & 0.629 & 0.668 & 0.573 \\
\hline$G_{x z}(\mathrm{GPa})$ & 0.542 & 0.814 & 1.08 & 2.32 & 1.88 & 2.32 & 4.27 & 2.31 & 2.14 \\
\hline$G_{z x}(\mathrm{GPa})$ & 0.570 & 0.855 & 1.14 & 2.35 & 1.98 & 2.46 & 4.12 & 2.31 & 2.15 \\
\hline$G_{y z}(\mathrm{GPa})$ & 0.361 & 0.542 & 0.724 & 1.54 & 1.25 & 1.54 & 4.27 & 2.30 & 2.13 \\
\hline$G_{z y}(\mathrm{GPa})$ & 0.363 & 0.547 & 0.731 & 1.56 & 1.28 & 1.61 & 4.30 & 2.35 & 2.20 \\
\hline$v_{x y}$ & 0.958 & 0.913 & 0.859 & 0.956 & 0.979 & 0.964 & 0.998 & 1.07 & 1.12 \\
\hline$v_{y x}$ & 0.941 & 0.879 & 0.808 & 0.951 & 0.970 & 0.949 & 1.01 & 1.10 & 1.17 \\
\hline$v_{x z}$ & 0.00767 & 0.0160 & 0.0259 & 0.0194 & 0.00356 & 0.00465 & 2.53 & 0.223 & 0.180 \\
\hline$v_{z x}$ & 0.330 & 0.330 & 0.330 & 0.856 & 0.307 & 0.335 & 2.59 & 0.930 & 1.02 \\
\hline$v_{y z}$ & 0.00753 & 0.0154 & 0.0244 & 0.0193 & 0.00353 & 0.00457 & 2.56 & 0.229 & 0.187 \\
\hline$v_{z y}$ & 0.330 & 0.330 & 0.330 & 0.856 & 0.307 & 0.335 & 2.59 & 0.930 & 1.02 \\
\hline
\end{tabular}

Figure $2 \mathbf{b}, V=$ volume and $A=$ cross-sectional area.

The above equation indicates that in order to achieve the same density for aluminum and composite cores, the thickness of the aluminum core wall must be made smaller by the ratio of raw material densities as follows:

$$
t_{\mathrm{Al}}=\frac{\left(\rho_{m}\right)_{\text {composite }}}{\left(\rho_{m}\right)_{\mathrm{Al}}} t_{\text {composite }}=(0.633) t_{\text {composite }}
$$

Tables 4 and 6 also show the ratio of the composite and aluminum cell properties. A ratio higher than one indicates that the corresponding property of the composite cell is larger than that of the aluminum. It can be seen that in most cases the composite has higher properties, especially for the transverse shear moduli $\left(G_{x z}\right.$ and $\left.G_{y z}\right)$, which are always higher for the composite core. These transverse moduli are essential in the design of sandwich panels since the core must be stiff enough in shear to ensure that the facesheets do not slide over each other when bending is present. In addition, no significant difference is seen between the "free wall" and "fixed wall" results for the properties not small or near zero $\left(E_{z}, v_{x y}\right.$, $v_{y x}, v_{z x}, v_{z y}, G_{x z}, G_{z x}, G_{y z}$ and $\left.G_{z y}\right)$ in Tables 4 and 6 .

\section{Summary and Conclusions}

A simplified finite element procedure to determine the equivalent engineering elastic moduli of a hexagonal cell core has been presented, including the appropriate boundary conditions that must be applied to a $1 / 8$ segment of a unit cell in order to replicate the behavior of the overall core. Using this method, values for the effective properties of hexagonal cell cores made of composite materials of various layups were presented. It was shown that the present method provides an accurate and practical way to incorporate the anisotropic and heterogeneous behavior of composite materials in the analysis of core properties. Furthermore, accurate values for the effective core properties are particularly important in the design of sandwich composite structures such as optical composite mirrors. Results for composite core showed that the transverse shear moduli are always higher than those of aluminum for the same core density. Additionally, if sandwich panels incorporate both composite facesheets and core, instead of aluminum core, then lower weights, increased stiffness, lower thermal distortion compatible with that of the facesheets, the absence of galvanic cor- 
rosion and the ability to readily modify the core properties to suit specialized needs can be achieved.

\section{REFERENCES}

[1] R. Atkinson, "Innovative Uses for Sandwich Constructions," Reinforced Plastics, Vol. 41, No. 2, 1997, pp. 3033.

[2] F. E. Penado, J. H. Clark III, J. P. Walton, R. C. Romeo and R. N. Martin, "Calculation of the Elastic Properties of a Triangular Cell Core for Lightweight Composite Mirrors," Proceedings of SPIE: New Developments in Optomechanics, San Diego, 26-30 August 2007, pp. B1-B8.

[3] R. C. Romeo and R. N. Martin, "Progress in 1 m-Class Lightweight CFRP Composite Mirrors for the ULTRA Telescope," Proceedings of SPIE: Optomechanical Technologies for Astronomy, Orlando, 24 May 2006, p. 62730 S.

[4] J. Hohe and W. Becker, "Effective Stress-Strain Relations for Two-Dimensional Cellular Sandwich Cores: Homogenization, Material Models, and Properties," Applied Mechanics Reviews, Vol. 55, No. 1, 2002, pp. 61-87. http://dx.doi.org/10.1115/1.1425394

[5] S. Kelsey, R. A. Gellatly and B. W. Clark, "The Shear Modulus of Foil Honeycomb Cores: A Theoretical and Experimental Investigation on Cores Used in Sandwich Construction," Aircraft Engineering and Aerospace Technology, Vol. 30, No. 10, 1958, pp. 294-302. http://dx.doi.org/10.1108/eb033026

[6] G. Hoffman, "Poisson's Ratio for Honeycomb Sandwich Cores," Journal of the Aerospace Sciences, Vol. 25, No. 8, 1958, pp. 534-535. http://dx.doi.org/10.2514/8.7765

[7] J. Zhang and M. F. Ashby, "The Out-of-Plane Properties of Honeycombs," International Journal of Mechanical Sciences, Vol. 34, No. 6, 1992, pp. 475-489. http://dx.doi.org/10.1016/0020-7403(92)90013-7
[8] L. J. Gibson and M. F. Ashby, "Cellular Solids: Structure and properties," Pergamon Press, Oxford, 1988.

[9] I. G. Masters and K. E. Evans, "Models for the Elastic Deformation of Honeycombs," Composite Structures, Vol. 35, No. 4, 1996, pp. 403-422. http://dx.doi.org/10.1016/S0263-8223(96)00054-2

[10] M. Grediac, "A Finite Element Study of the Transverse Shear in Honeycomb Cores," International Journal of Solids and Structures, Vol. 30, No. 13, 1993, pp. 17771788. http://dx.doi.org/10.1016/0020-7683(93)90233-W

[11] B. Kim and R. M. Christensen, "Basic Two-Dimensional Core Types for Sandwich Structures," International Journal of Mechanical Sciences, Vol. 42, No. 4, 2000, pp. 657-676. http://dx.doi.org/10.1016/S0020-7403(99)00028-4

[12] R. F. Gibson, "Principles of Composite Material Mechanics," McGraw-Hill, New York, 1994.

[13] C. W. Schwingshackl, G. S. Aglietti and P. R. Cunningham, "Determination of Honeycomb Material Properties: Existing Theories and an Alternative Dynamic Approach," Journal of Aerospace Engineering, Vol. 19, No. 3, 2006, pp. 177-183. http://dx.doi.org/10.1061/(ASCE)0893-1321(2006)19:3(1 77)

[14] C. C. Chamis, R. A. Aiello and P. L. N. Murthy, "Fiber Composite Sandwich Thermostructural Behavior: Computational Simulation," Journal of Composites Technology \& Research, Vol. 10, No. 3, 1988, pp. 93-99. http://dx.doi.org/10.1520/CTR10135J

[15] "COSMOS/M User Guide," Version 2.95, Structural Research and Analysis Corporation, Los Angeles, 2007.

[16] J. R. Andrews, F. E. Penado, S. T. Broome, C. C. Wilcox, S. R. Restaino, T. Martinez, S. W. Teare and F. Santiago, "Characterization of the Lightweight Telescope Developed for the NPOI," Proceedings of SPIE: Ground-Based and Airborne Telescopes, Orlando, 24 May 2006, p. 62673Q. 